\title{
AGIR NA GLOBALIZAÇÃO Condições e orientações da ação coletiva
}

\author{
Augusto Santos Silva \\ FEP, IS-UP, Porto, Portugal
}

Resumo A globalização exige maior enfoque na ação coletiva. O artigo pretende contribuir para a análise da questão. Examina as transformações em curso, quanto às condições de espaço e tempo e aos recursos de ação. Mostra, em particular, que as desigualdades face à mobilidade constituem hoje uma nova e crítica dimensão da fratura social. Retém depois os problemas de ação coletiva suscitados pela globalização, quer para a regulação dos desequilíbrios e assimetrias, quer para o seu encaixe nas estruturas políticas e sociais. Defende, por fim, que uma perspetiva orientada pelos valores da democracia, do direito e do desenvolvimento constitui um bom quadro de referência para identificar a agenda de reforma internacional e os seus protagonistas.

Palavras-chave: globalização, desenvolvimento, democracia.

Abstract Globalisation demands collective agency. This is the starting point of the article. First, it considers the ongoing changes regarding space-time and the resources for action. It points out that inequalities vis-à-vis mobility constitute a new and critical dimension of the social divide. Secondly, the article focuses on the prospects for collective agency in the context of globalisation, both for the regulation of its unbalances and for its embeddedness in social and political structures. Finally, one suggests that a perspective defined by the key values of democracy, justice and development can design a useful framework to formulate an agenda for international reform and to identify possible protagonists.

Keywords: globalisation, development, democracy.

Résumé La mondialisation réclame une nouvelle attention aux problèmes de l'action collective. Cet article offre une contribution à l'analyse de ces problèmes. Il considère les changements qui sont en cours, en ce qui concerne l'espace, le temps et les ressources de l'action. Il essaie notamment de montrer que les inégalités face à la mobilité représentent une dimension nouvelle et particulièrement critique de la fracture sociale. Ensuite, on approche les questions soulevées par la mondialisation soit à la régulation des déséquilibres et asymétries, soit à

l'encadrement de l'économie par les structures sociales et politiques. Finalement, on soutient qu'une perspective analytique orientée par les valeurs de la démocratie, du droit et du développement constitue un cadre approprié pour la définition d'un agenda de réforme internationale et pour l'identification de ses protagonistes.

Mots-clés: mondialisation, développement, démocratie.

Resumen La globalización exige un maior enfoque en la acción colectiva. Este artículo busca contribuir al análisis de la cuestión. Examina las transformaciones en marcha, en lo que respecta a las condiciones de espacio y tiempo y a los recursos para acción. Resalta, en particular, que las desigualdades frente a la movilidad constituyen actualmente una nueva y crucial dimensión de la fractura social. Enfoca, en seguida, los problemas de acción colectiva generados por la globalización, tanto para la regulación de los desequilíbrios e asimetrias, como para su ajuste en las estructuras políticas y sociales. Sostiene, por último, que una visión orientada por los valores de la democracia, de la ley y del desarollo constituye un buen marco para trazar la agenda de reforma internacional y sus protagonistas.

Palabras-clave: globalización, desarrollo, democracia. 


\section{Introdução}

A globalização é um processo social de muitas dimensões. A sua novidade histórica decorre do nível que nela atingiram (1) a compressão do espaço-tempo, (2) a integração sistémica e (3) a interdependência dos agentes, instituições e arenas que constituem o mundo. Isso não fez perder heterogeneidade, mas sim aumentá-la: em importantes aspetos, o mundo carateriza-se hoje por maior diversidade. Basta pensar nas múltiplas escalas que o organizam: de facto, quando falamos de processos globais, podemos estar a referir-nos à escala planetária (como na questão ambiental); à escala internacional (aquela em que, por exemplo, se decide a regulação do comércio mundial); à escala de entidades propriamente supranacionais (caso, entre outros, da União Europeia); à escala transnacional (nas identidades religiosas, na etnicidade, mas também nas empresas multinacionais ou no capital financeiro); e até, vamos dizer assim, às redes globais de entidades subnacionais (como as bem chamadas cidades globais). A globalização não é, pois, nem uma fatalidade histórica, nem muito menos o triunfo irreversível de uma política e de uma narrativa (a política do Consenso de Washington e a narrativa neoliberal). Nem é, ainda, uma explicação simples e operativa do que se passa no nosso tempo. A globalização é um processo geo-histórico, multidimensional e complexo, que carece de abordagem interdisciplinar - designadamente da parte de economistas, sociólogos, cientistas políticos, geógrafos e historiadores. Não é o que explica, mas sim o que deve ser explicado (sigo, em especial, Grataloup, 2013 [2007]; Rodrick, 2012; Sassen, 2007; Stiglitz, 2007 [2006]).

Ora, a globalização é um contexto da ação humana. Não apenas no sentido em que toda a estrutura social o é; também na medida em que a sua natureza multiescalar altera qualitativamente o quadro de desenvolvimento de qualquer ação: por mais local que esta pareça, o mundo todo faz-se ver nela. A operária têxtil portuguesa "concorre" com a sua colega vietnamita, a empregada paquistanesa trabalha, em Londres, numa cadeia multinacional de comida rápida, o governo mexicano interage com o Fundo Monetário Internacional, a mãe marroquina compra para o seu bebé comida de marca suíça fabricada em França. O cruzamento de escalas também se observa nos sistemas de valores e normas e nos padrões de comportamento: as identidades locais e nacionais dialogam com as grandes correntes hegemónicas mundiais, e estamos constantemente a ver isso nas roupas como nos gestos, nas línguas como nas emoções, vemo-lo em virtualmente todas as artes de ser e fazer do quotidiano social. Finalmente, a globalização também problematiza a arrumação canónica entre níveis de ação micro, meso e macro. Se continua a ser pertinente distinguir as pessoas e grupos domésticos, os grupos, organizações e classes, as instituições nacionais e internacionais, os estados e as sociedades civis, os blocos regionais e a comunidade internacional como um todo, não é menos certo que as inter-relações já não obedecem à típica hierarquia do menor para o maior e do mais perto para o mais longínquo.

A globalização significa, pois, um novo contexto estrutural para a ação humana. Significa também uma nova exigência. Como bem sintetizou o economista Joseph Stiglitz (2007 [2006]: 332), “a globalização implica uma maior integração 
dos países do mundo; esta maior integração implica uma maior interdependência e esta interdependência maior implica que haja mais ação coletiva". De entre, pois, as questões relativas à ação social no quadro da globalização, deve reservar-se uma atenção específica à "ação coletiva" que a toma por objeto ou ponto de partida, desenrole-se tal ação no plano governamental ou não governamental, nas relações entre estados ou no seio das sociedades civis, e assuma ou não a forma de estratégias propriamente políticas (e, nestas, de políticas públicas).

O presente artigo pretende contribuir para a modelização da análise sociológica destas questões. A primeira secção considerará sucintamente as transformações principais induzidas ou favorecidas pelo processo de globalização, no que respeita às condições de espaço e tempo e aos recursos de ação. Articulará, portanto, a assimetria no acesso a essas condições e recursos com a desigualdade nas demais dimensões estruturais. Depois, serão retidos os problemas de ação coletiva suscitados pela globalização: a segunda secção proporá uma interpretação da estrutura e dinâmica do sistema mundial; a terceira procurará definir a questão da regulação, ou governação global; a quarta, e última, identificará os eixos de narrativa e de agência por referência aos quais se pode conceptualizar a ação na e sobre a globalização.

\section{Espaço, tempo e ação}

Como o espaço e o tempo se encontram entre as variáveis mais determinantes na definição da situação em que, e perante a qual, a ação humana toma lugar, a compressão do espaço-tempo operada pelo processo de globalização há de representar uma mudança de vulto naquela definição. É habitual e pertinente sintetizá-la na palavra "mobilidade". Mas será útil demorarmo-nos um pouco no seu significado.

Mobilidade quer dizer, desde logo, facilidade de deslocação: circulação. De pessoas e de bens - e, nestes, quer de recursos ou fatores produtivos, como a informação, o trabalho ou o capital, quer de produtos, sejam bens ou serviços. A circulação pode ser física, fazendo uso das infraestruturas e meios de transporte; ou imaterial, através das redes de comunicações. A mudança qualitativa operada pela globalização diz respeito à intensidade, extensão e velocidade da circulação: circula-se mais, por mais espaço e em menos tempo.

Isto permite menos dependência e vinculação do ator que circula, ou faz circular, a um local físico e social específico. A ação depende menos de variáveis contextuais particulares, porque se tornou mais fácil, por exemplo, investir e desinvestir economicamente num dado território, ou porque as decisões podem ser tomadas a grande distância dos seus impactos, ou se pode jogar com as cotações de bolsa em turnos diários de 24 horas, considerando sucessivamente Tóquio, Londres e Nova Iorque. A vinculação social do ator tende a ser menor, ou menos constrangedora, porque o seu espaço de ação se alarga indefinidamente: a "lealdade" nacional de uma multinacional parece menos evidente, ou a crença religiosa de um migrante pode devir uma referência identitária e um quadro de comportamento mais forte do que o próprio país de origem. 
Os contextos de interação mudam, enfim, consideravelmente: a convergência entre a informática e as telecomunicações, a generalização da conectividade e a portabilidade dos dispositivos técnicos, dos computadores aos telemóveis, transformam radicalmente as condições. Fazem-no em comparação com a ordem mais tradicional das coisas: a interação pessoal já não exige copresença física, a comunidade de que alguém se sente mais próximo pode ser o círculo dos "amigos" ou "contactos" das redes sociais, mais do que as antigas redes de sociabilidade assentes na vizinhança, no trabalho ou no clube. Mas fazem-no também em comparação com a era da comunicação de massas do Pós-II Guerra: os grandes media perdem o seu quase monopólio na produção e circulação de informação e na oferta de símbolos e histórias suscetíveis de estruturar uma adesão emocional, porque os novos media (como os grandes agregadores e distribuidores de conteúdos digitais e as redes sociais) oferecem uma via paralela, mais acessível e interativa. Uns não suplantam os outros, tendendo antes a funcionar num regime misto de concorrência e complementaridade; mas os segundos repõem a possibilidade da comunicação "face a face" ou em pequeno círculo, agora num espaço-tempo virtual.

Estas três dimensões de mobilidade - mais circulação, menos vinculação, mais autonomia face ao contexto físico - não representam o término da territorialidade da ação humana. Aliás, tomada cada uma por si, nenhuma é original; original é, isso sim, a escala da sua combinação. A ação humana não se "libertou" do espaço e do tempo, nem se tornou "a-territorial". A relação entre ação e contexto é que se alterou; e o resultado tem sido a maior complexidade e a maior plasticidade de ambos.

A este ponto, já de si relevante, acrescenta o/a sociólogo/a logo outro: aqui se encontra uma nova zona de inscrição e forma de realização da fratura social. O relacionamento dos atores com o espaço-tempo e os seus recursos e práticas de mobilidade não são homogéneos ou equivalentes. A mobilidade divide, porque são desiguais as condições de acesso aos recursos e capacidades indispensáveis; e porque esta desigualdade reproduz e acentua as desigualdades sociais mais gerais. Eis uma das principais "consequências humanas" da globalização, como escreveu Zigmunt Bauman (1998: 6-26). Ao mesmo tempo que diminui as amarras territoriais do capital financeiro, da grande empresa e da elite social, a globalização prende uma parte importante da população ao território, localizando-a em função de necessidades heterónomas, mesmo quando, como no caso dos migrantes, a faz mover entre localizações. Há, nos termos de Saskia Sassen, uma "classe global" desenvolta na forma como usa, gere e reconstrói o espaço, a que pertencem altos funcionários internacionais, ou executivos e profissionais de topo; e uma "nova classe global de desfavorecidos", constituída por "indivíduos, categorias populacionais e organizações" que a globalização "imobiliza", porque estão vinculados à geografia dos poderes empresariais que procuram os recursos laborais onde eles existam ao menor custo e os subordinam a lógicas organizacionais e económicas globais (Sassen, 2007: 164-189).

Os atores sociais não se movem, pois, pelas mesmas razões e à mesma velocidade ou alcance. O capital financeiro é o mais móvel de todos os fatores, alguns dizendo que é a única arena em que faria verdadeiramente sentido usar a palavra 
"globalização" (cf. Bourdieu, 1998: 39-44). O trabalho é comparativamente menos móvel, muito mais sujeito a barreiras à circulação (sendo clandestina parte considerável dos migrantes).

A mobilidade é um produto e um produtor de desigualdades, quer internas a cada país, quer entre países e regiões do mundo (cf. Costa, 2012). A fratura decorrente não é aspeto menor da ordem social; pelo contrário, a sua importância aumenta com o crescimento e alargamento da mobilidade. Os transportes, as comunicações, o comércio, o investimento estrangeiro, e também a pobreza, os conflitos armados e as violações de direitos pessoais, todos produzem mobilidade de pessoas, ideias, coisas e riscos, ameaças ou oportunidades. Mas estas mobilidades são profundamente diferenciadas e desiguais. A globalização, essa, é feita de todas: dos capitais financeiros globais e das empresas multinacionais, dos viajantes frequentes em classes executivas e dos migrantes, dos turistas e dos refugiados, dos quadros e dos trabalhadores subalternos. O certo é que ninguém pode compreender o mundo de hoje se não tiver, por exemplo, em mente que o número de migrantes internacionais era estimado em 2013, pelas Nações Unidas, em 232 milhões de pessoas (48\% das quais mulheres), um aumento de $50 \%$ face a 1990 ; e que os imigrantes representavam $8 \%$ dos residentes na Rússia, $12 \%$ na Alemanha, na França ou no Reino Unido, 14\% na Espanha ou nos Estados Unidos, 21\% no Canadá, 28\% na Austrália, 31\% na Arábia Saudita... e 84\% nos Emiratos Árabes Unidos (United Nations, 2013: 1-9). A estrutura do mundo globalizado é, pois, como salientaram Scott Lash e John Urry (1994: 12-13), determinada pelos fluxos de capital, trabalho, mercadorias, informação e imagens; e uma sociologia ainda demasiado centrada nos lugares entendidos como espaços fixos não poderia apreendê-la plenamente.

Quem age são os atores, e esses não são entidades abstratas, nem as forças invisíveis do "Sistema" ou do "Poder". É preciso proceder a uma cuidadosa identificação, ponderando e distinguindo os diversos tipos de atores. Se, como ensina a teoria sociológica, a ação se desenvolve numa, e em ligação com uma, estrutura institucional e relacional (ver Scott, 2011: 140-213), o que é que muda quando é a globalização essa estrutura?

Ao contrário do que por vezes se diz, com mais veia doutrinária do que suporte empírico, os atores classicamente seriados pela sociologia não se tornaram, de um momento para o outro, evanescentes. Falo dos indivíduos, nos múltiplos papéis que desempenham e nas múltiplas condições de sujeito que os enformam; das famílias e grupos domésticos, dos pares e outros grupos de pertença e/ou referência; dos lugares e tecidos locais, das redes de vizinhança e outras ancoragens territoriais; das profissões e grupos socioprofissionais; das organizações e associações; das classes sociais e das identidades e movimentos de género, etnicidade, orientação sexual; das comunidades religiosas e outros agrupamentos de forte dimensão simbólica; das empresas, sindicatos e comissões de trabalhadores; dos media e outros fatores e carris de opinião pública; dos parlamentos, governos e administrações; da comunidade internacional como um todo e do seu sistema de organizações, bem como do direito internacional. A lista pretende ser variada, mas não exaustiva. Seria absurdo pretender que a globalização é a superação disto. Pelo contrário, como vários têm mostrado (mas veja-se a síntese de Saskia Sassen, 2007: 
47-96), mesmo o ator institucional que mais correntemente é declarado "ultrapassado" pela globalização - o estado nacional - foi e tem sido um ativo promotor da própria globalização. Quando as suas funções e poderes são "desestatizados" e "desnacionalizados", é ele que os desestatiza, privatizando-os, e desnacionaliza, entregando-os a entidades supranacionais.

Então que muda? O que muda - e obriga a atualizar o quadro da análise sociológica - são fundamentalmente três aspetos. Primeiro, a forma de articulação e organização dos atores, através da emergência de redes, como formas alternativas (às clássicas) de mobilizar e reunir atores em instâncias coletivas de ação. Assim, as redes tornam-se elas próprias atores sociais (cf. Castells, 2002-2003 [1996-1998]), mais difusos mas não menos operativos do que os clássicos atores de nível mesossociológico que nos habituáramos a considerar, como a empresa, o bairro ou o grupo social.

Depois, como já notámos, a mobilidade acrescenta uma vantagem significativa aos atores globais: menos vinculados aos territórios e fronteiras, logo, à regulação pública, eles são mais fugidios e nómadas, e por isso parecem, aos desapossados, sem rosto e inalcançáveis. De facto, a multinacional que ora está aqui ora parte para bem longe é um interlocutor muito diferente do industrial estabelecido do fordismo, com o qual se estabelecia um modus vivendi mais ou menos turbulento. Os "mercados financeiros", esse novo Leviatão capaz de derrubar estados, não se personificam em vozes e lideranças concretas, e contudo parecem dispor de vontade e as suas "emoções" são sondadas e temidas; são redes de bancos, seguradoras, fundos, investidores e intermediários de variado tipo. O concorrente cuja ascensão (legal ou com dumping) provoca a falência da nossa firma e a perda do emprego, podemos nunca tê-lo visto e ele pode estar a milhares de quilómetros de onde a nossa ação sindical, política ou cívica consegue chegar.

Muda, enfim, uma terceira coisa, que é a liderança das instituições políticas e estatais na condução da ação internacional. Ela nunca foi tão desafiada como agora, e por efeito da globalização. A emergência e o protagonismo de atores e redes com real impacto político, mas que não assumem a clássica forma do estado, têm consequências notórias. As mais perturbadoras são, de um lado, a nova ameaça representada por atores políticos e militares não estatais, que hoje representam a principal fonte de insegurança global (não a única, mas a principal) - as organizações terroristas, as redes de tráfico de pessoas, armas e droga, os senhores e bandos de guerra, são exemplos elucidativos; e, do outro lado, a disrupção das formas de regulação herdadas do Pós-Guerra (inspiradas nos acordos de Bretton Woods), induzida (ou acelerada) por forças económicas capazes de mudar a geopolítica, como é tão nitidamente o caso dos mercados de capitais financeiros.

Aqui, mais uma vez, a sociologia pode chamar a atenção para dois tópicos que nem sempre são valorizados pelas ciências vizinhas. O primeiro é a globalização da questão da segurança, entendida como defesa de territórios e ordem pública e também como proteção e bem-estar de pessoas (security + safety). A alteração do quadro de segurança dado por garantido pelas opiniões públicas - estruturado pelo estado nacional e as relações entre estados - gera perceções e sentimentos de insegurança que podem, por sua vez, mudar qualitativamente as procuras sociais 
de proteção e estabilidade e a sua definição de riscos, perigos, alianças e conflitos (cf. Burgess, 2012 [2010]). Ora, a este descentramento corresponde um outro, e é esse o segundo tópico que a sociologia pode ajudar a compreender melhor. Como escreve Zygmunt Bauman (1998: 68), que por sua vez convoca Claus Offe, "a separação da economia face à política e a sua isenção da intervenção regulatória result[a] num desempoderamento da política como uma agência efetiva, [tornando-a] problemática". Este esvaziamento ou enfraquecimento da política, como esfera própria e determinante da ação coletiva, tem um potencial de desapossamento social que não é negligenciável. É que as populações integradas, ao longo dos séculos XIX e XX, no estado liberal e (subsequentemente) democrático, veem diminuir o alcance, sobre os poderes fáticos, do seu meio principal de influência, que é a participação e representação política. E isso desperta ou acentua reações de muito difícil gestão política, desde o absentismo até à contestação desinstitucionalizada, desde o fechamento soberanista até à xenofobia. Aos olhos de uma parte relevante da opinião pública, a globalização parece estender incomensuravelmente o escopo da ação cívica (multiplicando, por exemplo, a capacidade de mobilização, pelo uso de redes sociais, ou de denúncia crítica e difusão de atitudes alternativas); e reduzir de forma igualmente avassaladora o alcance da ação cívica, isto é, a possibilidade de provocar a mudança social agindo politicamente no quadro das instituições estabelecidas (cf. Beck, 2006 [1986]: 400-407).

\section{Estrutura e dinâmica do sistema mundial}

Aumentando a integração e a interdependência do sistema mundial, a globalização requer, como já vimos, mais ação coletiva, concertada. Um número crescente de questões deixou de poder ser colocado apenas ou primacialmente ao nível de cada nação e de cada bloco de nações. O internacional cede o passo ao propriamente global.

O enfrentamento da situação tem uma dimensão normativa e uma dimensão analítica. Focar-nos-emos nesta, que é onde a sociologia pode contribuir mais para aquela. Dois pontos são aqui críticos. Um respeita à caraterização estrutural e dinâmica do sistema mundial; o outro, à sua governação.

O que mais se destaca, quanto ao primeiro, é justamente o enorme dinamismo do sistema. Todas as tentativas, meritórias, de classificá-lo em categorias estanques se têm revelado limitadas, face à sua plasticidade e constante evolução. Por um lado, as escalas disponíveis - a que distingue centro e periferia, a que distingue nacional, supra e subnacional e a que distingue global e local - cruzam-se, produzindo combinatórias muito diversificadas (cf. Santos, 2001: 56-77). Por outro lado, a estrutura do sistema não é uniforme em todas as arenas relevantes; pelo contrário, se, com o fim da Guerra Fria, o mundo deixou de ser bipolar em termos político-ideológicos, abriu-se espaço para o desenvolvimento de várias polarizações, consoante consideremos a centralidade económica, o poderio militar estatal, a vitalidade demográfica, as identidades religiosas e civilizacionais...

A descrição analítica tem, pois, de ser tão ágil quanto se revela ser a realidade. Isso não quer dizer abandonar as categorias, o que seria renunciar a qualquer 
análise. Significa usá-las com flexibilidade. A geoeconomia pode ser caraterizada através da tensão entre grandes áreas centrais, como a América do Norte, a União Europeia e a Ásia-Pacífico. Mas também o pode ser pelo jogo entre centralidades mais localizadas - levando por exemplo a identificar as duas fachadas atlântica e pacífica dos Estados Unidos e a megalópole que, nos Grandes Lagos, articula Estados Unidos e Canadá; ou a "banana azul" europeia que vai do sul do Reino Unido ao norte de Itália (e o seu prolongamento em direção dos países nórdicos); ou o Japão, o litoral da China (as suas regiões económicas especiais) e pelo menos a Coreia do Sul. Em 2016, o jogo entre centros está mais aberto: os Estados Unidos “deslocam-se" para o Pacífico, ou contrabalançarão esse movimento com o reforço, ou pelo menos manutenção, do laço transatlântico? Faz ainda sentido falar, no atual estado da relação entre o Reino Unido e o continente europeu, em Estados Unidos de um lado e União Europeia do outro, ou será mais adequado pensar na contraposição entre o sistema económico-institucional anglo-americano e os sistemas europeus continentais? Aproximar-se-ão entre si os modelos asiáticos - o modelo dos estados desenvolvimentistas da expansão do Pós-Guerra, como o Japão e os chamados Tigres, e o modelo chinês, de produção industrial e mão de obra intensiva no quadro dos "dois sistemas", coexistindo o controlo político com a economia não regulada de mercado? Esta escala regional (isto é, supranacional), mas com claros pontos de apoio nacionais, é a mais operativa? Ou o "centro" geoeconómico está hoje na concatenação de territórios económicos globais localizados em diferentes países e sistemas institucionais - como as "megalópoles mundiais" de que falava Olivier Dolffus (1997: 25-32), no fim dos anos 90, ou as "cidades globais" de que fala Saskia Sassen (2007: 97-128)? E mesmo essoutra maneira de conceptualizar a mudança geoeconómica, resistirá ela à emergência cada vez mais nítida de conglomerados globais que, ou são empresas multinacionais organizadas como redes, ou são mesmo fundos financeiros que tomam essas mesmas empresas, não como projetos de investimento duradouro, mas como oportunidades de gerar valor monetário mais ou menos imediato?

E, depois, como dar conta da geoeconomia em mudança? A distinção de Immanuel Wallerstein (1979) é operativa: centros e periferias do sistema mundial, com as funções de intermediação a ser tendencialmente desempenhadas por semiperiferias. Quando se pensa no posicionamento de Portugal e Espanha na União Europeia, é difícil não notar o seu papel efetivo ou potencial de articulação entre a União e África e a América Latina. Mas para além das periferias existem margens, que uma coisa é estar nos lugares subalternos de um sistema hierárquico, outra é estar fora dele. A globalização económica tem de facto produzido a maior marginalização do que não tem integrado: um caso flagrante é o conjunto da África Subsariana, em contraste com o Sul e Sudeste da Ásia. Mesmo aí, pode sugerir-se, como faz o geógrafo Christian Grataloup (2013 [2007]: 38-39), que "para lá" das margens se estão constituindo novas centralidades pelo menos regionais, como se verifica no Cone Sul de África. Logo, precisamos de não acabar nas categorias, mas começar com as categorias; não moldar a realidade a elas, e sim adaptá-las à realidade movente. Centros, periferias, margens, novas centralidades... 
Importa também situar as categorias no tempo: o que está hoje consolidado pode ser amanhã desestruturado, o motor de agora pode vir a gripar; e o jogo entre centros estabelecidos e centralidades emergentes é um jogo de geoeconomia $e$ de geopolítica na plenitude do sentido de ambas as expressões. Veja-se o impasse vivido, há décadas, pelo Japão; aquele experienciado pela Zona Euro desde a Grande Recessão de 2008 e a Grande Estagnação que se lhe seguiu; as hesitações estratégicas dos decisores políticos e empresariais norte-americanos. E, evidentemente, já não é totalmente apropriado referirmo-nos ao BRIC - Brasil, Rússia, Índia e China - para dar conta das "economias emergentes". Pois, de uma banda, outras economias vêm mostrando o seu potencial, sendo difícil esquecer, pelo menos, outros países do G20; e, da outra banda, é muito diversa a situação conjuntural e estrutural dos BRIC.

Flexibilidade das categorias, atenção ao espaço-tempo na sua aplicação: eis dois eixos fundamentais da modelização sociológica do agir global. Mas a sociologia de vocação holística tem mais uma coisa a dizer às ciências vizinhas: que é preciso articular a dimensão económica com outras, se quisermos perceber as várias polarizações que estão em curso e se entrechocam no mundo de hoje. As economias são sistemas sociais: inscrevem-se em, e regulam-se por instituições legais, políticas, culturais, territoriais... A maior ameaça à pujança económica da China não está no desequilíbrio demográfico? Não é este mais difícil de corrigir do que a hiperdependência face ao mercado externo? O inverno demográfico não é outra ameaça estrutural a países como a Rússia ou o Japão? As fontes e as redes de abastecimento energético não configuram uma determinante maior da evolução económica? E, para a União Europeia e para a Rússia, a insegurança e a desestruturação político-administrativa dos seus anéis de segurança - do Magrebe e do Sahel ao Médio Oriente, para a primeira, do Médio Oriente à Ásia Central e do Sul, para a segunda - não representam questões económicas críticas, para além de políticas?

Este esforço de interligação de dimensões que a organização disciplinar das ciências sociais tende demasiadas vezes a desprezar é ainda importante para compreender que não há uma, mas várias polarizações estruturando o sistema mundial. É verdade que, no plano geoestratégico, o fim da Guerra Fria, em 1989, ditou a passagem de um sistema bipolar, marcado pela rivalidade entre Estados Unidos e União Soviética, para um sistema que, no que toca ao poderio militar estatal, é unipolar, sendo os Estados Unidos a superpotência que resta. A Rússia de Putin procura agora alterar esta relação de forças. A estrutura da geoeconomia, essa, é mais tripolar - Estados Unidos, União Europeia, Ásia-Pacífico - mas, como vimos, em geometria variável e evolutiva. Como não ver, porém, outras polarizações? Aquela que contrapõe, de um lado, a ordem internacional baseada nos estados e no sistema das Nações Unidas e, do outro, a pulverização de atores não estatais e não regulados e dos riscos e ameaças que transportam? Aquela que se estrutura na dialética da laicidade e do fundamentalismo de inspiração ou justificação religiosa? Ou na nova e fortíssima polarização político-ideológica que, desde os anos 80 até hoje, se tem consolidado entre o "neoliberalismo" e a "economia social de mercado", quer dizer, entre o primado do mercado ou o primado da democracia - e de que as narrativas sobre a globalização são uma expressão lapidar? 


\section{A regulação da globalização}

Seria pobre, pois, toda e qualquer caraterização sociológica da estrutura do sistema mundial, em época de globalização, que não lhe mostrasse o dinamismo, abertura e flexibilidade. Ora, esta prevenção adquire todo o sentido quando se trata, analiticamente, do problema dito da governação da globalização: dado que o processo existe, em toda a sua multidimensionalidade, como, para quê e através de que meios se pode intervir nele?

Do ponto de vista analítico, a primeira coisa a fazer é situá-lo em perspetiva histórica. Na sua forma e dimensão atual, a globalização representa uma mudança maior do nosso tempo, na transição entre os séculos XXe XXI. Contudo, há dinâmicas de internacionalização e mundialização bem anteriores, podendo remontar-se muito atrás na geo-história (cf. Grataloup, 2013 [2007]). Para os propósitos de agora, é sobretudo útil ter em conta o seguinte: depois do fim do grande ciclo oitocentista de mundialização unipolar, centrada no Reino Unido, e da longa "guerra civil" europeia de 1914 a 1945, o sistema de Bretton Woods foi montado de forma a orientar a regulação da economia internacional para a maximização das vantagens e a minimização dos riscos que ela poderia causar ao sistema económico e social de cada nação. Como explica Dani Rodrick (2012: 69-76), as instituições de Bretton Woods - o FMI, o Banco Mundial e o GATT - concretizavam um regime multilateral cuja finalidade era o estímulo moderado do comércio internacional e a compatibilização de políticas económicas e monetárias críticas, na perspetiva de que isso seria um trunfo na agenda interna de cada país. O que terá sucedido, na passagem para a lógica da Organização Mundial do Comércio (OMC), foi a inversão dessa perspetiva: a agenda interna tornou-se subsidiária da agenda global. "A globalização tornou-se um imperativo, que aparentemente requer que todas as nações prossigam uma estratégia comum de baixa fiscalidade sobre as empresas, política orçamental restritiva, desregulação e enfraquecimento dos sindicatos" (Rodrick, 2012: 76; cf. também Stglitz, 2007 [2006]).

A perspetiva histórica é muito importante porque relativiza o que o pensamento ideológico quer absolutizar. Mas não significa reduzir a nossa ação à celebração mais ou menos nostálgica de um passado que a memória agora doura; nem muito menos autoriza que se olhe para o presente com as lentes de outrora. Não faz, pois, sentido reproduzir, tal qual, o debate histórico entre mercantilismo e laissez faire. E mesmo o que foi realmente operativo antes dos anos 70 não tem fatalmente de o ser agora. Além do mais, como já vimos, os atores que fizeram Bretton Woods não dispõem hoje da razão e da força de então - precisamente por causa do curso da globalização.

Devemos situar as coisas no tempo, olhar para o passado mas não querer repeti-lo. Por conseguinte, o que mais importa, no quadro da análise das possibilidades e orientações da ação coletiva, é identificar bem o problema. Ora, o problema não é a globalização; ou melhor, enunciá-lo assim, genérica e abstratamente, em nada ajuda a circunscrevê-lo. Seria preciso ser mais específico. Em si, a compressão do espaço-tempo, a maior integração sistémica, a maior interdependência e a diversidade e heterogeneidade do mundo não são factos nem fatores catalogáveis 
sem mais, como "bons" ou "ruins". Depois, é impressionante o registo da globalização económica em matéria de crescimento, geração e difusão de inovação, redução da chamada pobreza absoluta. O comércio, o investimento e a mobilidade dos recursos têm sido potentes motores do desenvolvimento em muitas partes do mundo - constituindo oportunidades de que vários países souberam tirar partido, outros não, e é necessário indagar porquê, caso a caso. Também a problematização de várias questões como questões globais permitiu avanços significativos na concertação de respostas a problemas críticos, na área da saúde pública e, em particular, das pandemias, na segurança cooperativa ou no ambiente. Mais uma vez, é matéria de investigação e explicação circunstanciada saber porque é que foi possível, por exemplo, pôr em prática uma estratégia comum, bem-sucedida, de combate ao buraco na camada de ozono e porque demorou tanto a mobilização mundial para o enfrentamento das alterações climáticas, até que o Acordo de Paris tivesse finalmente lugar, em 2015. Do ponto de vista sociológico, a formulação do problema, para ser pertinente, tem de ser operativa.

Visto da perspetiva que fundou o consenso do Pós-Guerra, ou seja, a maior aproximação possível ao que Ralf Dahrendorf (1996 [1995]) chamou a "quadratura do círculo" - um jogo de soma positiva entre liberdade política, crescimento económico e coesão social - o problema da globalização é duplo. De um lado, um problema de assimetria, isto é, desigualdade e desequilíbrio. Do outro, o seu encaixe institucional, quer dizer, a combinação da escala global de circulação e mobilidade com a escala nacional ou subnacional da cidadania.

O uso do termo de assimetria sugere que o debate sobre a globalização não pode ser reduzido à troca de argumentos a favor ou contra a "liberalização". O que se entende por liberalização? Se é o levantamento de barreiras à mobilidade dos fatores e produtos, então deve dizer-se que há dimensões em que essa liberalização avançou imenso, e talvez a questão seja verificar se isso gera ou não externalidades negativas - é o caso da circulação dos capitais; e há dimensões em que as restrições permaneceram ou até, em parte, aumentaram, e há espaço para reduzi-las - é o caso da circulação da mão de obra (Rodrik, 2012: 266-272). Se as barreiras à liberalização forem consideradas na sua multiplicidade (e não apenas as administrativas e explícitas), então há de chamar-se a atenção para que a abertura do comércio internacional está por concluir exatamente em áreas onde os países em desenvolvimento retirariam mais benefícios. É o que se passa com a agricultura e a indústria agroalimentar, em que a forte subsidiação pública da produção própria, pelos Estados Unidos, a União Europeia ou o Japão, distorce o "comércio livre" (cf. Stglitz, 2007 [2006]: 121-122). Ganha-se, pois, em precisão analítica quando se evita a incorporação acrítica de bandeiras doutrinárias, como se fossem categorias autojustificadas, e se procura reformular as coisas de acordo com uma linguagem conceptual mais clara.

O que se consegue, a meu ver, quando se coloca o foco sobre as questões de (des)igualdade e de (des)equilíbrio. Aquelas conduzem-nos ao poder - à estrutura de poder do sistema económico e geopolítico mundial. Joseph Stiglitz (2007 [2006]) fez uma demonstração cabal da centralidade dessa estrutura, que não vale a pena repetir aqui. Apenas salientar, do ponto de vista sociológico, quanto se imbricam as 
dimensões económica, política e estratégica. O comércio internacional, o investimento externo, o jogo entre políticas monetárias e orçamentais e outras formas de regulação da atividade económica são arenas de relações de poder entre atores políticos da máxima grandeza; e organizações como a OMC são o palco em que essas relações continuamente se desenrolam. Elas articulam-se com domínios igualmente cruciais como o direito das patentes (e a sua travagem da disseminação de conhecimentos e técnicas, mesmo as mais úteis para o desenvolvimento social planetário, designadamente na área dos medicamentos), a segurança e o abastecimento energético, a preservação da biodiversidade, etc. O poder e a desigualdade são, pois, ângulos analiticamente mais úteis, para pensar a globalização, do que outros demasiado próximos da narrativa ideológica (como "abertura", "liberalização", "desregulamentação" ou mesmo "modernização"). São também úteis para pensar a ação na e perante a globalização - até porque sugerem que, mais produtivo do que o puro protesto ou o propósito de "pará-la", será procurar rebalanceá-la do ponto de vista da distribuição mundial de recursos e oportunidades.

Este rebalanceamento impõe-se ainda noutro aspeto - para o qual pretendo reservar o termo de equilíbrio. Refiro-me à rede de interdependências que estrutura o sistema mundial, ligando os atores. Se o critério da (des)igualdade assinala os fatores geradores e os efeitos gerados em termos de assimetrias no acesso às fontes de produção e distribuição de riqueza e bem-estar, o critério do (des)equilíbrio faz realçar as assimetrias nos papéis e nas possibilidades de ação dos diferentes atores, como os estados, as organizações regionais e internacionais de estados, as agências públicas mundiais e as organizações não governamentais. O rumo da globalização - e, em particular, da globalização económica, bem entendidas também as suas consequências sobre as restantes dimensões - depende muito da relação de forças e da capacidade diferencial de influência desses atores. Quer na determinação da agenda, quer na tomada de decisões e nas condições da sua implementação. A sociologia da globalização não pode, pois, e por exemplo, dispensar-se de analisar as mudanças no direito internacional, público e privado, ou de caraterizar as grandes instituições hegemónicas no atual quadro de globalização (como o Tesouro norte-americano ou os bancos centrais dos Estados Unidos, da Zona Euro, do Reino Unido, do Japão ou da China, ou o Fundo Monetário Internacional, ou a Organização Mundial do Comércio, ou as principais agências de rating) como o que elas são: fontes, sistemas e atores de poder político. E não pode, também por exemplo, deixar de comparar os recursos, mandatos e métodos de agências como a Organização Internacional do Trabalho e a Organização Mundial do Comércio, ou o Banco Mundial e o Programa das Nações Unidas para o Desenvolvimento, ou a OCDE e a UNESCO, para dar conta da dinâmica geopolítica como tal.

O primeiro problema que uma perspetiva analítica comprometida com a lógica da chamada economia social de mercado identifica é, pois, esta dupla assimetria: desigualdades e desequilíbrios constituintes da globalização, ou a ela associados. Ao segundo problema chamámos já o seu encaixe institucional.

Para o olhar sociológico, trata-se de um encaixe duplo. De um lado, aquele que a economista institucionalista e outras alternativas ao paradigma puramente neoclássico põem em evidência. Os sistemas económicos são diversos entre si - 
há, designadamente, vários capitalismos (cf. Amable, 2005). E, ainda mais importante, os sistemas económicos não são apenas "mercados", nem combinações de "mercados" e "estados", mas sim estruturas complexas de atividades e trocas incrustadas e articuladas com territórios, organizações, escolhas políticas, instituições (cf. Reis, 2009 [2007]: 31-117). Assim, a questão analítica que nenhum estudo da globalização pode esquecer é a do seu impacto sobre a capacidade de encaixe institucional das economias - a economia mundial no seu todo, ou as várias economias regionais, ou cada economia nacional de per si. Há três níveis em que o encaixe é fundamental: com a respetiva estrutura social (as populações e os seus recursos); com a respetiva estrutura normativa (as populações e os seus valores); com a respetiva estrutura política (as populações e a sua cidadania). Como vimos, o espírito de Bretton Woods era partir dessas estruturas e tomá-las como limites do esforço de internacionalização e de regulação internacional; inversa tem sido a atitude reinante na OMC. O que dá espaço e razão para conceber possíveis rebalanceamentos.

Há, porém, outro lado, menos percorrido pela teoria económica, mas que é complementar e coerente com o seu. Trata-se já não apenas do encaixe da economia globalizada nas diversas estruturas nacionais, mas da articulação entre si das múltiplas dimensões da globalização, que esta mesma tornou mais integradas e interdependentes. Destaco as dimensões económica, geoestratégica (e, em particular, da segurança) e ambiental. Ao contrário do que faz crer a ideologia neoliberal da globalização, a economia não é a dimensão matricial a partir da qual se deve pensar a evolução sistémica do mundo, mas apenas uma entre várias dimensões, decerto muito relevante. Eé de outra base que se deve partir para pensar e influenciar a articulação, a base que possa vinculá-la às preferências e decisões dos atores soberanos. O seu nome é: política.

\section{Narrativas e protagonistas}

É este o desafio: como é que a ação coletiva há de reequilibrar o processo de globalização, de modo a (1) favorecer a redistribuição de recursos e poderes julgada indispensável para corrigir assimetrias, reduzir desigualdades e pôr em prática jogos de soma positiva entre os atores implicados; e (2) permitir que a globalização articule melhor as suas múltiplas dimensões e se encaixe na diversidade de histórias, culturas e valores das diferentes sociedades. Assim colocado, o desafio pode ser enunciado, na esteira de Dani Rodrik, como "um paradoxo", a incompatibilidade entre as democracias nacionais e a "hiperglobalização" (Rodrik, 2012: 188). Daí um "trilema político": "não se pode ter ao mesmo tempo a globalização, a democracia e a autodeterminação nacional". Ou se globaliza a democracia, criando uma governação democrática mundial; ou se renuncia à soberania, e portanto, à autonomia e diversidade societal; ou se limita o escopo e alcance da globalização, regulando-a a partir de finalidades mais amplas do que o crescimento do comércio mundial ou a agilidade dos mercados financeiros (Rodrik, 2012: 200-205).

A resposta de Rodrik dá prioridade à democracia; reconhece que é por referência a cada sociedade e comunidade política (ou estado) nacional que ela melhor 
se realiza, porque assim se respeita melhor a singularidade de cada história e identidade, a diversidade das formas societais e a vontade soberana de cada conjunto de cidadãos; e defende que a intervenção sobre a globalização deve torná-la instrumental para os objetivos democráticos. O que pede uma maior regulação (global) da globalização, e também no sentido da sua contenção. Para o que são necessárias transformações nas estruturas de governação mundial, existentes ou emergentes, compatibilizando-as com esse princípio de respeito pela singularidade e a autonomia decisória de cada povo.

Esta resposta não é estruturalmente diferente da que dá, também a partir da economia, Joseph Stiglitz (2007 [2006]), ou, na perspetiva das relações internacionais e das suas interdependências, Joseph Nye Jr. (2011 [2000]). Ela identifica bem a tensão dialética entre os três polos do dilema - essa tensão que as representações determinísticas da globalização olimpicamente ignoram; e pode, portanto, servir-nos para enquadrar analiticamente as múltiplas condições e possibilidades da ação coletiva.

Ora, a gestão da tensão implica, pelo menos, a convocação de dois elementos fundamentais. Um é de natureza cognitiva e normativa: como interpretamos e avaliamos a globalização, os seus efeitos e limites; e que consequências retiramos em termos de escolhas e finalidades de ação. Chamemos-lhe "metanarrativa". O outro é de índole prática: saber com que protagonistas e em que quadros institucionais será mais eficiente estabelecer essa necessária regulação global da globalização.

De uma perspetiva europeia, a consequência principal da globalização hegemónica desde os anos 80 sobre as doutrinas e as políticas foi a desestruturação e, até certo ponto, deslegitimação das "narrativas" fundadoras do desenvolvimento económico e do consenso social do Pós-II Guerra: a democracia cristã e a social-democracia. Em particular, a globalização pôs em causa aquilo que Tony Judt (2009 [2005]: 633) crismou de "Grande Narrativa do século XX": a combinação entre democracia política, keynesianismo e estado-providência. As dificuldades de adaptação reveladas por esta narrativa, em contraste com a força da gestão dita neoliberal da globalização, potenciaram os sinais de rutura que Daniel Sassoon (2001 [1996]: 269, 438) descreveu como a "grande crise do socialismo" europeu dos fins do século XX, ou Judt (2010: 140) como "a linguagem exausta da social-democracia". Sinais de alarme equivalentes (embora menos estudados) encontram-se do lado da democracia cristã.

Não é este o lugar para uma discussão mais ideológica (pertinente e necessária) destes sinais. A análise sociológica pode, contudo, ajudar a identificar o problema e definir um quadro para essa discussão. Se as respostas políticas são certa e felizmente variáveis, haveremos, ao menos, de nos entender sobre os eixos temáticos em torno dos quais se pode (re)construir uma metanarrativa crítica sobre a globalização.

Vislumbro três eixos.

O primeiro é a democracia, como armadura institucional para a participação tão alargada quanto possível, nos processos de tomada, aplicação e avaliação de decisões, de pessoas, movimentos e organizações. Ela permite conceptualizar a relação entre, de um lado, as tendências fortes, "objetivas", da evolução socioeconómica e, do outro, a formação e representação dos interesses e vontades dos grupos 
sociais dela protagonistas ou a ela sujeitos. Permite também, o que não é menos relevante, enquadrar os processos de participação social em sistemas de freios e contrapesos que equilibram as relações de força e contrabalançam as derivas soberanistas, meramente reativas face à globalização e, por isso, incapazes de contribuir para a sua regulação. Como bem salienta Todorov (2012), a democracia é um incentivo à participação e um desincentivo à desmesura.

O segundo eixo é o direito, como sistema de normas e instituições de relação e interdependência, gerais e abstratas, fundadas na igualdade perante a lei. Dois pontos me parecem, aqui, decisivos. Um é geral e respeita à necessária tensão entre a liberdade individual de cada agente e a lei que define o campo da sua ação por referência à inter-relação com os outros, protegendo cada agente face aos abusos de poder dos restantes. O outro é específico do direito internacional, conquanto define um quadro de princípios, costumes e atos convencionais que retira as dinâmicas entre estados do simples império da força e as rodeia de compromissos e acordos normativos capazes de enformar quer o relacionamento bilateral, quer o relacionamento multilateral entre os estados e nas organizações internacionais. Ora avulta, como verdadeira "pedra angular" do direito internacional público (Alland, 2016 [2014]: 12, 283-297), a questão da resolução dos diferendos, seja no que respeita ao princípio geral da resolução pacífica, seja no que importa às práticas de resolução por negociação entre as partes, por mediação de terceiros, por arbitragem ou por jurisdição internacional; e não é difícil encontrar aqui matéria muito relevante para pensar a regulação das interdependências que a globalização acentua, das conflitualidades que lhes estão associadas e dos objetivos e modos de agir que os coletivos empreendem, para enfrentá-las.

O terceiro eixo é o desenvolvimento, como processo económico e social de capacitação e empoderamento de atores, organizações e territórios, prosseguindo objetivos e caminhos da sua própria escolha (cf. Sen, 2010 [2009]). Neste domínio, a via teoricamente mais fecunda parece ser a que explora os conceitos de desenvolvimento humano e de desenvolvimento sustentável (cf., por exemplo, UNDP, 2014; UNWCED, 1987) no quadro da chamada Agenda 2030, isto é, da prossecução dos Objetivos do Desenvolvimento Sustentável, definidos, em 2015, pelas Nações Unidas (cf., também por exemplo, United Nations, 2016). O que apresenta diversas vantagens, mas uma essencial: afirmar que esses objetivos - e, portanto, toda a problemática do desenvolvimento - dizem respeito a todos os países e nações. Todos têm obrigações de desenvolvimento a cumprir e, portanto, lacunas e incompletudes a suprir; todos, e não apenas os "pobres", os "periféricos" ou os "atrasados".

A globalização precisa, portanto, de metanarrativas que lhe confiram o quadro de sentido que a abertura das fronteiras, a liberdade de circulação e a inovação tecnológica não bastam para construir. A democracia, o direito e o desenvolvimento podem estruturar essa metanarrativa, essa maneira de representar o mundo e discorrer sobre ele, suficientemente ampla para integrar as múltiplas e, tantas vezes, antagónicas narrativas que os diversos interesses e pontos de vista sociais tendem a gerar.

Quanto aos protagonistas, o que o/a sociólogo/a pode dizer é que a dinâmica da ação coletiva em torno da globalização dependerá crucialmente da relação entre 
três forças: o sistema internacional, quer dizer, o conjunto de relações internacionais construídas pela ação multilateral de estados soberanos; as entidades supranacionais, de dimensão regional, em construção; e as redes de interação e ação concertada de movimentos e organizações sociais, com destaque para as de natureza não governamental.

A reforma do sistema internacional não é tanto uma matéria de grande engenharia organizacional como de reequilíbrios adaptativos e disseminação de boas práticas. Por exemplo, os avanços conseguidos na governação de questões globais de saúde pública podem inspirar as autoridades noutros domínios (cf. Elbe, 2012). Mas é impensável um modelo de regulação da globalização que se revele efetivo sem a reconsideração da estrutura multilateral por excelência, o sistema das Nações Unidas, e do modo como nela se "encaixam" os instrumentos hoje disponíveis para a governação económica global, da OCDE à OMC e do G7 ao G20.

Na sua extensão e ambição, a União Europeia continua a representar uma entidade supranacional sui generis. Para além, evidentemente, das debilidades de arquitetura (e proficiência) institucional, de que outros falarão melhor do que sociólogos, importa não perder de vista que o problema fundamental continua sendo aquele que Manuel Castells (2002-2003 [1996-1998]: III, 454-455) assinalou logo nos últimos anos 90: como é que a "Europa" pode representar uma "identidade de projeto", capaz de respeitar a sua própria e densa geografia de identidades nacionais e sociais e, ao mesmo tempo, integrá-las e desenvolvê-las por referência a um horizonte normativo e praxeológico comum?

Finalmente, no que toca aos atores não governamentais globais, as enormes potencialidades de concertação proporcionadas pela globalização das comunicações e pelas estruturas de organização em rede permitem conceptualizar um "espaço público" global, capaz também de alicerçar uma "sociedade civil" mundial. Do ponto de vista analítico, que é o que releva para este artigo, o cuidado fundamental a ter é evitar uma representação idílica, puramente doutrinária, de tal espaço público, como se ele fosse, por definição, imune aos interesses e às relações de forças. Pelo contrário, é a sua representação como sistema de poder que melhor contribui para o reequilíbrio da ordem internacional, exatamente porque contrapõe outros atores e outros poderes àqueles que, na esfera financeira e política, mais têm pressionado a seu favor a dinâmica da globalização.

Agir na globalização e agir perante a globalização representam, pois, desafios qualitativamente novos para as sociedades, as instituições e os atores. A análise sociológica pode e deve contribuir para a caraterização desses desafios. E não será uma contribuição menor, tendo em vista o seu enfrentamento por todos os implicados.

\section{Referências bibliográficas}

Alland, Denis (2016 [2014]), Manuel de Droit International Public, Paris, Presses Universitaires de France (3..$^{a}$ edição revista).

Amable, Bruno (2005), Les Cinq Capitalismes. Diversité des Systèmes Economiques et Sociaux dans la Mondialisation, Paris, Editions du Seuil. 
Bauman, Zygmunt (1998), Globalization. The Human Consequences, Cambridge, Polity Press.

Beck, Ulrich (2006 [1986]), La Société du Risque. Sur la Voie d'Une Autre Modernité, Paris, Flammarion (tradução).

Bourdieu, Pierre (1998), Contre-Feux. Propos pour Servir à la Résistance contre l'Invasion Néo-Libérale, Paris, Liber-Raisons d'Agir.

Burgess, J. Peter (org.) (2012 [2010]), The Routledge Handbook of New Security Studies, Londres, Routledge.

Castells, Manuel (2002-2003 [1996-1998]), A Era da Informação. Economia, Sociedade e Cultura, 3 vols., Lisboa, Fundação Calouste Gulbenkian (tradução).

Costa, António Firmino da (2012), Desigualdades Sociais Contemporâneas, Lisboa, Mundos Sociais.

Dahrendorf, Ralf (1996 [1995]), A Quadratura do Círculo, Lisboa, Edições 70 (tradução).

Dollfus, Olivier (1997), La Mondialisation, Paris, Presses de Sciences Po.

Elbe, Stefan (2012 [2010]), "Pandemic security", em J. Peter Burgess (org.), The Routledge Handbook of New Security Studies, Nova Iorque, Routledge, pp. 163-172.

Grataloup, Christian (2013 [2007]), Géohistoire de la Mondialisation. Le Temps Long du Monde, Paris, Armand Colin.

Judt, Tony (2009 [2005]), Pós-Guerra. História da Europa desde 1945, Lisboa, Edições 70 (tradução).

Judt, Tony (2010), Um Tratado sobre os Nossos Actuais Descontentamentos, Lisboa, Edições 70 (tradução).

Lash, Scott, e John Urry (1994), Economies of Signs and Spaces, Londres, Sage Publications.

Nye Jr., Joseph S. (2011 [2000]), Compreender os Conflitos Internacionais. Uma Introdução à Teoria e à História, Lisboa, Gradiva (tradução).

Reis, José (2009 [2007]), Ensaios de Economia Impura, Coimbra, Edições Almedina.

Rodrick, Dani (2012), The Globalization Paradox. Democracy and the Future of the World Economy, Nova Iorque, W. W. Norton.

Santos, Boaventura de Sousa (2001), “Os processos da globalização”, em Boaventura de Sousa Santos (org.), Globalização. Fatalidade ou Utopia?, Porto, Edições Afrontamento, pp. 31-106.

Sassen, Saskia (2007), A Sociology of Globalization, Nova Iorque, W. W. Norton.

Sassoon, Donald (2001 [1996]), Cem Anos de Socialismo. A Esquerda Europeia Ocidental no Século XX, Lisboa, Contexto (tradução).

Scott, John (2011), Conceptualising the Social World. Principles of Sociological Analysis, Cambridge, Cambridge University Press.

Sen, Amartya (2010 [2009]), A Ideia de Justiça, Coimbra, Edições Almedina (tradução).

Stiglitz, Joseph E. (2007 [2006]), Tornar Eficaz a Globalização, Porto, Edições Asa (tradução).

Todorov, Tzvetan (2012), Os Inimigos Íntimos da Democracia, São Paulo, Companhia das Letras (tradução).

United Nations (2013), International Migration Report, 2013, Nova Iorque, United Nations.

United Nations (2016), Global Sustainable Development Report, 2016, Nova Iorque, Department of Economic and Social Affairs. 
UNDP - United Nations Development Program (2014), 2014 Human Development Report. Sustaining Human Progress. Reducing Vulnerabilities and Building Resilience, Nova Iorque, UNDP.

UNWCED - United Nations World Commission on Environment and Development (1987), Our Common Future, Oxford, Oxford University Press.

Wallerstein, Immanuel (1979), The Capitalist World-Economy, Cambridge, Cambridge University Press.

Augusto Santos Silva (corresponding author). Professor da Faculdade de Economia e investigador do Instituto de Sociologia da Universidade do Porto, Rua Dr. Roberto Frias, 4200-464 Porto, Portugal. E-mail: asilva@fep.up.pt

Receção: 18 de setembro de 2016 Aprovação: 12 de dezembro de 2016 